\title{
Postnatal Care Service Utilization and Associated Factors among Mothers Who Delivered in Shebe Sombo Woreda, Jimma Zone, Ethiopia
}

\author{
Fantaye Chemir ${ }^{1 *}$, Melkamu Gelan ${ }^{2}$ and Makeda Sinaga ${ }^{3}$ \\ ${ }^{1}$ School of nursing and midwifery, Jimma University, Ethiopia \\ ${ }^{2}$ School of nursing and midwifery, Jimma University, Ethiopia \\ ${ }^{3}$ School of nursing and midwifery, Jimma University, Ethiopia
}

*Corresponding author: Fantaye Chemir, School of Nursing and Midwifery, Jimma University, Ethiopia

\begin{abstract}
Background: Postnatal care is a critical period for both mothers and newborns survival. But, post-natal care is yet neglected; little attention and an effort have been paid by health care providers and policy makers in developing countries. Post-natal care service utilization is still low and maternal mortality rate is high. However, studies on postnatal care service utilization and associated factors are lacking in the study setting. Therefore, the aim of this study is to assess postnatal care service utilization and associated factors among mothers who delivered in Shabe sombo woreda, Jimma zone, Oromiya region, South West Ethiopia, 2018.
\end{abstract}

Methods: A community based cross-sectional study design was conducted in Shabe sombo woreda, Jimma zone. A total of 564 study participants were included in the study using simple random sampling technique. Data was collected from March 1 - April 1, 2018. Data was entered into Epi data version 3.1 and exported into SPSS version 23.0 for analysis. Bivariate and multivariable logistic regression analysis was made in order to predict factors associated with postnatal care (PNC) service utilization.

Result: The study revealed that the magnitude of PNC service utilizations is $58.5 \%$. Multivariable logistic regression analysis showed that, mothers with younger age (adjusted odds ratio $(\mathrm{AOR})=2.243,(95 \% \mathrm{Cl}: 1.066,4.721)$, having antenatal care visit $(\mathrm{AOR}=9.36,95 \% \mathrm{Cl}: 5.605,15.618)$, experiencing obstetric complication during pregnancy (AOR $=2.3373,95 \% \mathrm{Cl}: 1.095,5.142$ ), who had information about PNC (AOR $=9.946,95 \% \mathrm{Cl}: 6.009,16.460)$ and appointed for PNC follow-up (AOR = 2.114, 95\% Cl: 1.289, 3.466) were more likely to utilize postnatal care services.
Conclusion: Though the finding showed that postnatal care service utilization was high when compared to other studies done in country, it was a lot behind from the national target of postnatal care service utilization in Ethiopia. The initiative of provision of information, education, counseling and communication both at the community and facility level should be strengthened.

\section{Keywords}

Postpartum care, Postnatal care, Service utilization, Women

\begin{abstract}
Abbreviations
A.A: Addis Ababa; AOR: Adjusted Odds Ratio; ANC: Antenatal Care; COR: Crude Odds Ratio; EDHS: Ethiopia Demographic and Health Survey; HEW: Health Extension Workers; MMR: Maternal Mortality Rate; PNC: Postnatal Care; PPC: Postpartum care; TT: Tetanus Toxoid; SNNPR: Southern Nation and Nationality Representatives
\end{abstract}

\section{Introduction}

Postnatal care is the care provided to the mother and their babies within 42 days after delivery [1].

Most maternal and infant deaths occur in the first month after birth. About $45 \%$ of postnatal maternal deaths occur within the first 24 hours and $66 \%$ occur during the first week [1,2]. Globally, the Maternal Mortality Rate is 216 per 100,000 live births, in sub-Saharan Africa 546 per 100,000 live births in 2015 [3]. In Ethiopia MMR was 412 per 100000 live births [4].

The post-natal period is a dangerous time for both

Citation: Chemir F, Gelan M, Sinaga M (2018) Postnatal Care Service Utilization and Associated Factors among Mothers Who Delivered in Shebe Sombo Woreda, Jimma Zone, Ethiopia. Int J Womens Health Wellness 4:078. doi.org/10.23937/2474-1353/1510078

Accepted: September 27, 2018: Published: September 29, 2018

Copyright: (c) 2018 Chemir F, et al. This is an open-access article distributed under the terms of the Creative Commons Attribution License, which permits unrestricted use, distribution, and reproduction in any medium, provided the original author and source are credited. 
mother and newborn infant. More than 500,000 women who die each year due to complications of pregnancy and childbirth in developing countries, most deaths occur during or immediately after childbirth [5].

The WHO recommends that a woman and her baby should be assessed by health professionals within one hour of birth and again after discharge from a facility. First visit should be during the first 24 hours after delivery and follow-up contacts are recommended at 2-3 days, 6-7 days and 6 weeks [6].

According to study conducted in American Collage Obstetrician and Gynecologist $40 \%$ of the mothers do not attend post-natal care visits [6].

In Ethiopia it is reported that only $17 \%$ of the mothers received postpartum care within the critical first two days after delivery and $81 \%$ of the women did not receive postpartum care. In Oromiya region of Ethiopia, only $9 \%$ of the mothers received postpartum care within the critical first two days after delivery [4].

Reduce global maternal mortality to less than 70 per 100,000 live births between 2016 and 2030 is one of international community's political agenda especially in view of the increased attention on the Sustainable Development Goals [7].

Safe motherhood remains a major challenge in sub-Saharan Africa and Ethiopia is no exception as the rates of maternal mortality (412 per 1,000 live births) and neonatal mortality rate (29 per 1,000 live births) still remains very high [4].

It was well known that most of maternal and newborn deaths could be prevented if essential interventions like postnatal care service in existing health care packages reached all women and their new-born. However, PNC service has been underutilized in Ethiopia in general and in the study area in particular. So, this study calls for identification of factors that influence women's utilization of postnatal care services in the study setting.

\section{Methods and Materials}

\section{Study area and period}

Shebe Sombo woreda is one of the 18 districts of Jimma zone. It is $52 \mathrm{~km}$ far from Jimma town to south West direction and $352 \mathrm{~km}$ far from Addis Ababa, the capital city of Ethiopia. The boundaries of Shebe Woreda are Seka woreda in the North, Manna Woreda in the East, SNNP in the South, and Kersa woreda in the West direction. The word was administratively divided in to 22 kebeles. The total population of shabe woreda is estimated to be 150,795 of which 74500 are males and 76295 are females (Census 2007). Numbers of women in reproductive age group (1549) are estimated to be 33,325 and numbers of mothers having birth in the past 12 month are 3244 . This study was conducted from March 1 to April 1, 2018.

\section{Study design}

A community based cross sectional study design was employed.

\section{Source of population}

All mothers who gave births in last 12 months in shebe Sombo woreda.

\section{Study population}

Sampled mothers who gave birth in the last 12 months in shebe Sombo woreda.

\section{Sample size determination and sampling procedure}

The sample size was determined using the single population proportion formula by considering $33.5 \%$ proportion of PNC service utilization from the study conducted in Debre Markos Town, North western Ethiopia [8] with a marginal error of $5 \%$ between the sample and the population at $95 \%$ confidence level. Considering $10 \%$ non-response rate and design effect of 1.5 , the final sample size was 564 .

From the total of 22 kebeles found in the district, 7 kebeles were selected by using lottery method. The total sample size was proportionally allocated for the selected kebeles based on their catchment number of mothers to obtain required number of study participants. Then lists of eligible mothers who live in the selected Kebeles were obtained from woreda health office to serve as a sampling frame and the study participants were selected by using simple random sampling method.

\section{Measurement}

The data was collected with face to face interview using pretested and structured questionnaire which was adopted from previously done similar researches, which contain four parts. The first part is socio-demographic characteristics; the second part is reproductive and obstetrics characteristics of the mother, the third part is awareness of mothers and barriers to PNC service utilization and the final part was about health care provider and accessibility related factors. The questionnaire was prepared in English language and then translated into Afan Oromo and Amharic by language experts and again translated back to English to maintain consistency. Finally, both Afan Oromo and Amharic version was used to collect data. The questionnaire was pre-tested by taking 5 percent of the sample size at Seka woreda and necessary modification was made based on the nature of gaps identified.

Data was double entered in to Epi data manager and was cleaned and explored for outliers, missing values and any inconsistencies.

\section{Data Collection}

The data was collected by six midwives from other woreda using the predesigned questionnaire. Two supervisors with first degree had trained and supervised the data collection process closely. To ensure the quality of data, two days training was given for data collectors and supervisors on the objective and relevance of 
the study, how to gather the appropriate information, procedures of data collection techniques and the whole contents of the questionnaire.

\section{Data Analysis}

After data collection, each questionnaire was coded and entered in to Epidata manager and was exported to SPSS version 23.0 for analysis. Descriptive statistics and binary logistic regressions analysis were performed. In the binary logistic regression, both bivariate and multivariate analyses were carried out. All the variables were entered in to bivariate analysis and those explanatory variables with a $p$ value $<0.25$ in crude analysis was considered as a candidate for multivariate analysis and those variables with a $p$ value $<0.05$ in multivariate analysis was considered as a significant predictor of postnatal care service utilization. Finally, the result of the analysis was presented in texts, tables and graphs as appropriate.

\section{Conceptual Definitions}

Postnatal period: The first six weeks starting immediately after the time of delivery.

Postnatal care (PNC): The care provided to the mother for a period of the first six weeks starting immediately after the time of delivery.

Postnatal care service utilization: Mother who attend at least one PNC service from health institutions by health professional (midwife, nurse, health officer, and medical doctor) or health extension worker during the first six weeks starting immediately after the time of delivery and at any set up within the first seven days of delivery after discharged from health facility.

Early postnatal care: The period from time of discharge from health facility to seven days of delivery.

Late postnatal care: The period from seven days to six weeks.

Access to health facility: Mother being no more than an hour from health facility or availability of health facility within one-hour travel by local means of transportation (foot, horse).

Knowledge: Awareness of the factors, situation, the fact, information and understanding that one has gained about PNC and how to utilize it through learning and experience.

\section{Ethical Consideration}

Ethical clearance letter was granted from Institutional Review Board (IRB) of Jimma University. A formal letter of cooperation from the Shebe woreda health office was assured prior to data collection. The respondents were informed about the purpose of the study, \& their oral and written consent was obtained. The respondents' right to refuse or withdraw from filling out the questionnaire was fully maintained. The information provided by each respondent was kept strictly confidential.

\section{Results}

A total of 544 mothers who gave birth for the last one year prior to the study period were participated in the study with a response rate $97.4 \%$. The non-response rate was the result of respondents' unwillingness to participate.

\section{Socio-demographic and obstetric characteristics}

The mean age of the mothers was 27.77 (SD of \pm 7.23) years. Regarding marital status and religion, 504 (92.6\%) and 319 (58.6\%) of them were married and Muslim respectively. Among all respondents, 332 (61\%) were Oromo by ethnicity. With regard to educational status, almost half 280 (51.5\%) of mothers and 241 (44.3\%) of husbands were non-educated. Regarding occupational status, $338(71.3 \%)$ of mothers were house wife and 327 (60.1\%) husbands were farmers Table 1.

Table 1: Socio-demographic characteristics of respondents in Shebe Woreda, Jimma Zone, Oromiya Region, Ethiopia, 2018 $(\mathrm{N}=544)$.

\begin{tabular}{|c|c|c|c|}
\hline \multicolumn{2}{|c|}{ Characteristics } & \multirow{2}{*}{$\begin{array}{l}\text { Number } \\
106\end{array}$} & \multirow{2}{*}{\begin{tabular}{|l} 
Percept \\
19.5
\end{tabular}} \\
\hline Age & $<20$ & & \\
\hline & $20-34$ & 326 & 60.5 \\
\hline & $35-49$ & 109 & 20 \\
\hline \multirow[t]{4}{*}{ Marital status } & Married & 504 & 92.6 \\
\hline & Single & 20 & 3.7 \\
\hline & Divorced & 14 & 2.6 \\
\hline & Widowed & 6 & 1.1 \\
\hline \multirow[t]{3}{*}{ Religion } & Muslim & 319 & 58.6 \\
\hline & Orthodox & 151 & 27.8 \\
\hline & Protestant & 74 & 13.6 \\
\hline \multirow[t]{6}{*}{ Ethnicity } & Oromo & 332 & 61 \\
\hline & Amhara & 91 & 16.7 \\
\hline & Gurage & 20 & 3.7 \\
\hline & Dawaro & 40 & 7.4 \\
\hline & Wolayitta & 14 & 2.6 \\
\hline & Kefa & 47 & 8.6 \\
\hline \multirow[t]{2}{*}{ Residence } & Urban & 113 & 20.8 \\
\hline & Rural & 431 & 79.2 \\
\hline \multirow[t]{3}{*}{ Income } & $<500$ & 263 & 48.3 \\
\hline & $500-1500$ & 143 & 26.3 \\
\hline & $>1500$ & 138 & 25.4 \\
\hline \multirow{4}{*}{$\begin{array}{l}\text { Maternal } \\
\text { education }\end{array}$} & No education & 280 & 51.5 \\
\hline & Primary education & 171 & 31.5 \\
\hline & $\begin{array}{l}\text { Secondary } \\
\text { education }\end{array}$ & 73 & 13.4 \\
\hline & Above secondary & 20 & 3.7 \\
\hline \multirow{4}{*}{$\begin{array}{l}\text { Husband } \\
\text { education }\end{array}$} & No education & 241 & 44.3 \\
\hline & Primary education & 204 & 37.5 \\
\hline & $\begin{array}{l}\text { Secondary } \\
\text { education }\end{array}$ & 72 & 13.2 \\
\hline & Above secondary & 27 & 5.0 \\
\hline \multirow{4}{*}{$\begin{array}{l}\text { Maternal } \\
\text { Occupation }\end{array}$} & House wife & 388 & 71.3 \\
\hline & Merchant & 79 & 14.5 \\
\hline & Daily labourer & 50 & 9.2 \\
\hline & Employer & 27 & 5 \\
\hline \multirow{4}{*}{$\begin{array}{l}\text { Husband } \\
\text { Occupation }\end{array}$} & Farmer & 327 & 60.1 \\
\hline & Merchants & 124 & 22.8 \\
\hline & Employer & 50 & 9.2 \\
\hline & Daily labourer & 43 & 7.9 \\
\hline
\end{tabular}


Table 2: Obstetric complication faced by mothers during pregnancy and after delivery at shabe sombo woreda, Jimma zone, Oromiya, Ethiopia, 2018.

\begin{tabular}{|c|c|c|c|c|c|}
\hline \multicolumn{2}{|l|}{ Characteristics } & \multicolumn{2}{|l|}{ Yes } & \multicolumn{2}{|l|}{ No } \\
\hline & & No & percent & No & Percent \\
\hline \multirow[t]{6}{*}{ Complication faced during pregnancy } & Vaginal bleeding & 18 & 3.3 & 526 & 96.7 \\
\hline & Severe headache & 27 & 5 & 517 & 95 \\
\hline & Abdominal pain & 7 & 1.3 & 537 & 98.7 \\
\hline & Blurring vision & 21 & 3.9 & 523 & 96.1 \\
\hline & No/poor infant movement & 12 & 2.2 & 532 & 97.8 \\
\hline & High grade fever & 2 & 0.4 & 542 & 99.6 \\
\hline \multirow[t]{6}{*}{ Complications faced after delivery } & Heavy bleeding & 36 & 6.6 & 508 & 93.4 \\
\hline & High grade fever & 10 & 1.8 & 534 & 98.2 \\
\hline & Severe headache & 9 & 1.7 & 535 & 98.3 \\
\hline & Blurring vision & 20 & 3.7 & 524 & 96.3 \\
\hline & Abdominal pain & 13 & 2.4 & 531 & 97.6 \\
\hline & Offensive vaginal discharge & 9 & 1.7 & 535 & 98.3 \\
\hline
\end{tabular}

Table 3: Type of PNC services provided for mothers after delivery, in Shebe Woreda, Jimma Zone, Oromiya, Ethiopia, 2018 ( $\mathrm{N}=318$ ).

\begin{tabular}{|l|l|l|l|l|}
\hline Type of PNC service & Yes & \multicolumn{3}{l|}{ No } \\
\hline & Frequency & $\%$ & Frequency & \% \\
\hline Physical examination for mother & 165 & 30.3 & 153 & 48.2 \\
\hline Physical examination for baby & 161 & 50.6 & 157 & 49.4 \\
\hline Provision of family planning & 252 & 79.2 & 66 & 20.8 \\
\hline Provision of immunization & 243 & 76.4 & 75 & 23.6 \\
\hline Advising on danger signs after delivery & 142 & 44.7 & 176 & 55.3 \\
\hline Advising on nutrition & 144 & 45.2 & 174 & 54.8 \\
\hline Advising on hygiene & 143 & 45 & 175 & 55 \\
\hline Advising on breast feeding & 147 & 46.2 & 171 & 53.8 \\
\hline
\end{tabular}

Table 4: The main reasons (barrier) mothers why they did not attend PNC services after delivery, in Shebe Woreda, Jimma Zone, and Oromiya, Ethiopia, $2018(\mathrm{~N}=544)$.

\begin{tabular}{|c|c|c|c|c|}
\hline \multirow[t]{2}{*}{ Variable } & \multicolumn{2}{|c|}{ Yes } & \multicolumn{2}{|c|}{ No } \\
\hline & No & $\%$ & No & $\%$ \\
\hline Culture & 117 & 21.5 & 427 & 78.5 \\
\hline Waiting for falling off of baby's cord stump & 139 & 25.6 & 405 & 74.4 \\
\hline To have enough energy & 128 & 23.5 & 416 & 76.5 \\
\hline Pregnancy unplanned & 46 & 8.5 & 498 & 91.5 \\
\hline Lack of time & 146 & 26.8 & 398 & 73.2 \\
\hline Lack of guardians for my children & 83 & 15.3 & 461 & 84.7 \\
\hline Waiting the service kill the time & 55 & 10.1 & 489 & 89.9 \\
\hline Lack information (advice) & 142 & 26.1 & 402 & 73.9 \\
\hline Health professionals were not care client in good manner & 44 & 8.1 & 500 & 91.9 \\
\hline
\end{tabular}

\section{Obstetrics complications and reproductive health characteristics of mother}

Three hundred fifty-one (64.5\%) of the mothers had had ANC follow up during their recent pregnancy. More than half 356 (65.4\%) of them had a planned and supported pregnancy. Out of all the respondents, 405 (74.4\%) had no history of abortion. Majority 406 (74.6\%) of the mothers had given two or more births. A significant number of mothers faced complications during pregnancy 65 (11.9\%), at time of delivery 108 (19.9\%) and after delivery 84 (15.4\%). The most common obstetric complications faced by mothers during pregnancy and after delivery were severe headache $27(5 \%)$ and heavy bleeding $36(6.6 \%)$ respectively (Table 2 ).

Awareness of mothers towards PNC service utilization
Three hundred forty-two (62.9\%) of mothers had ever heard about PNC services after delivery. The main source of information for mothers about PNC services were health professionals 326 (59.9\%), women developmental army 148 (27.2\%), and community conversation 75 (13.8\%). More than half 341 (62.1\%) of the mothers know the availability of PNC and 303 (55.7\%) mothers know that postnatal period was more dangerous to the life of mothers and their babies.

\section{Magnitude of PNC utilization}

Of the total respondents, 318 (58.5\%) were utilized postnatal care service after delivery within six weeks of their last birth (Figure 1). Most of the mothers 252 (79.2\%) received family planning services followed by child immunization 243 (76.4\%) services during their postnatal care visit (Table 3 ). 
Table 5: Health facilities and health care providers and utilization of postnatal care service utilization in Shebe Woreda, Jimma zone, Oromiya region, Ethiopia, 2018.

\begin{tabular}{|l|l|l|l|}
\hline Variable & & Number & Percent \\
\hline Time taken from mother's & $2 \mathrm{hr}$ & 317 & 58.3 \\
\cline { 2 - 4 } home to health facility & $>2 \mathrm{hr}$ & 227 & 41.7 \\
\hline Place of delivery & Home & 112 & 20.6 \\
\cline { 2 - 4 } & Health Center & 320 & 58.8 \\
\hline & Health Post & 32 & 5.9 \\
\hline & Hospital & 80 & 14.7 \\
\hline Delivery attendants & $\begin{array}{l}\text { Health } \\
\text { profession }\end{array}$ & 320 & 73.3 \\
\hline & HEW & 56 & 10.3 \\
\hline & TBA & 89 & 16.4 \\
\hline $\begin{array}{l}\text { Having appointment for } \\
\text { PNC }\end{array}$ & Yes & 265 & 48.7 \\
\hline $\begin{array}{l}\text { Advised possible } \\
\text { postpartum complications } \\
\text { by health profession }\end{array}$ & Yes & 279 & 51.3 \\
\hline No & 306 & 56.3 \\
\hline $\begin{array}{l}\text { Advised possible newborn } \\
\text { complications by health } \\
\text { profession }\end{array}$ & Yes & 238 & 43.8 \\
\cline { 2 - 4 } & No & 314 & 57.7 \\
\hline
\end{tabular}

Nearly half $41.5 \%$ of the study participants did not attended PNC care service with the main perceived barrier of time shortage 145 (26.7\%) and lack information 141 (25.9\%) (Table 4).

\section{Health facilities and health care providers' related factors}

It took up to 2 hours to reach the health facility on foot for the majority of respondents 317 (58.3\%). The study finding revealed 432 (79.4\%) of the mothers gave their last births at health facilities. Three hundred six $(56.3 \%)$ and $314(57.7 \%)$ of the mothers were advised by the health professionals on possible postpartum maternal and new-born complications respectively (Table 5).

\section{Factors associated with postnatal care service uti- lization}

Bivariate analysis of the data revealed the variables, maternal age, ethnicity, marital status, history of abor-

Table 6: Multivariate logistic regression analysis of postnatal care service utilization among woman delivered in shabe sombo woreda, Jimma zone, Oromiya region, Ethiopia, 2018.

\begin{tabular}{|c|c|c|c|c|c|}
\hline \multirow[t]{2}{*}{ Variables } & & \multicolumn{2}{|c|}{ PNC Utilization } & \multirow{3}{*}{$\begin{array}{l}\text { COR 95\% CI } \\
2.17(1.54,4.66)^{*}\end{array}$} & \multirow{3}{*}{$\begin{array}{l}\text { AOR 95\% Cl } \\
2.243(1.066,4.721)^{\star \star}\end{array}$} \\
\hline & & \multirow{2}{*}{\begin{tabular}{|l|} 
Yes \\
271
\end{tabular}} & \multirow{2}{*}{\begin{tabular}{|l|} 
No \\
164 \\
\end{tabular}} & & \\
\hline Age & $<35$ & & & & \\
\hline & $>35$ & 47 & 62 & 1 & \\
\hline \multirow[t]{2}{*}{ ANC follow up } & Yes & 276 & 75 & $13.2(8.63,20.2)^{*}$ & $9.356(5.605,15.68)^{* *}$ \\
\hline & No & 42 & 151 & 1 & \\
\hline \multirow{2}{*}{$\begin{array}{l}\text { Complication during } \\
\text { pregnancy }\end{array}$} & Yes & 48 & 17 & $2.18(1.22,3.91)^{\star}$ & $2.373(1.095,5.142)^{* *}$ \\
\hline & No & 270 & 209 & 1 & \\
\hline \multirow[t]{2}{*}{ Information about PNC } & Yes & 275 & 67 & $15.2(9.87,23.2)^{*}$ & $9.946(6.009,16.40)^{* *}$ \\
\hline & No & 43 & 159 & 1 & \\
\hline \multirow[t]{2}{*}{ PNC appointment } & Yes & 201 & 64 & $4.34(3.009,6.28)^{*}$ & $2.114(1.289,3.466)^{* *}$ \\
\hline & No & 117 & 162 & 1 & \\
\hline
\end{tabular}

NB. ${ }^{*}=p<0.25(\mathrm{COR}),{ }^{* *}=p<0.05(\mathrm{AOR})$ significantly associated, 1 = Reference.

\section{PNC Service}

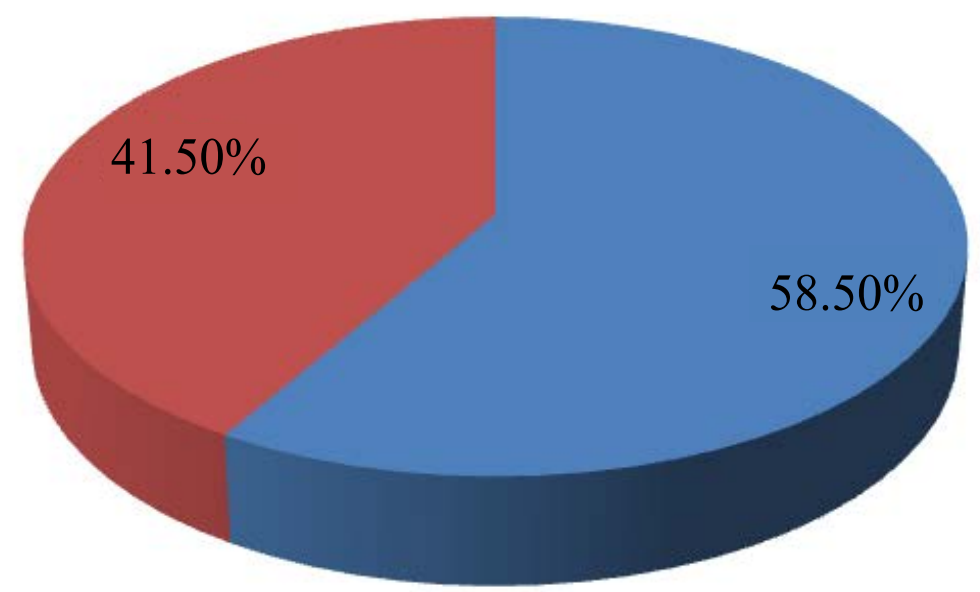

PNC Service Utilized PNC Service Not Utilized

Figure 1: The prevalence of postnatal care service utilization among mothers, who delivered in Shebe Woreda, Jimma Zone, Oromia region, Ethiopia, 2018.

Magnitude of postnatal care service utilization. 
tion, husband occupation, maternal occupation, monthly household income, information about PNC, previous history of obstetric complication during pregnancy, complication after giving birth, ANC follow up, place of delivery, delivery attendant, distance of residence from health facility, PNC appointment by health profession, advised postpartum maternal and newborn complication before discharge were found to be candidate for multivariable logistic regression model with a $p$-value < 0.25 .

The variables with $p$-value less than 0.05 in multivariate analysis were taken as having a statistically significant association with PNC service utilization and the rest were refuted from analysis. Those variables found to be a significant predictor for PNC service utilization were maternal age, ANC follow up on last delivery, complication during pregnancy, having information about PNC and appointed for PNC. It was shown that mothers who will utilize PNC service were likely to be: whose age < 35 years $(A O R=2.24,95 \% \mathrm{Cl}: 1.06,4.72)$, having ante natal care follow up (AOR $=9.36,95 \% \mathrm{Cl}: 5.605,15.618)$, had history of obstetric complication during pregnancy (AOR $=2.33,95 \% \mathrm{Cl}: 1.09,5.14)$, who heard about PNC service (AOR $=9.94,95 \% \mathrm{Cl}: 6.01,16.46$ ) and appointed for PNC visit $(A O R=2.11,95 \% \mathrm{Cl}: 1.28,3.46)$ as compared to their counterparts (Table 6).

\section{Discussion}

The findings of this study showed that among 544 postpartum women, 318 (58.5\%) obtained PNC during the first 6 weeks following delivery. This result is high compared with studies done in different areas (Arsi zone, Oromiya (23.4\%) [9], Debra markos Town, Amhara (33.5\%) [8], Halaba Kulito, SNNPR (47.9\%) [10], Wolayitta, SNNPR (34.31\%) [11], North Eastern Nigeria (16.9\%) [12] and Nepal (43.2\%) [13]. This may be attributed to the time difference that there could be improvement in accessing and utilizing health care service through time and other factors could be attributed to place, and social context variation between this study and previous studies.

But, this study finding was lower as compared to other studies (Gulele Sub City, Addis Ababa, Ethiopia (89.2\%) [14] and Adwa town, Tigray, Ethiopia (78.3\%) [15]. This is may be attributed to the difference in time, study setting (more of urban, study subjects could have better accessible and awareness about health services in the study from Addis Ababa, the capital of Ethiopia).

Young mothers more likely utilize postnatal care service than older one. This finding is supported by local studies conducted in Wolayitta Zone, SNNPR [11], and in addition it is similar with a study conducted in Pakistan [16], from a review on African country [17]. This can be justified younger mothers are more likely to have greater exposure and more access to education.

Mothers who attended ANC follow up before giving their last birth were more likely to utilize PNC service than those mothers who not attended ANC visit at all. This result is in line with the studies conducted Gondar, Ethiopia [18], Nepal [13], Pakistan [16]. The possible explanation for the strong positive association between ANC attendance and PNC service utilization might be that mothers and their families receive health education and counselling and advice during ANC visits and thus become access to learn about the benefits of PNC services follow up in health care facilities.

Mothers who faced health problems before their last birth appear strongly interested to seek postnatal care than mothers who had no experience of obstetric complication. This result is supported by a local study done in Gondar, Ethiopia [18], Tigray, northern Ethiopia [19] and other study done in Nepal [13]. The possible explanation could be that mothers who had history of complication sign have practical experience about the life treating conditions than those who did not. This experience could motivate the mother to attend ANC and give birth at health facility.

Women who had information about PNC were more likely to utilize PNC than those who didn't ever hear. This is consistent with studies done in Addis Ababa, Ethiopia [14], Adigrat town and Enderta District, Tigray Ethiopia [15,19], Jabitena, Ethiopia [20], Nepal [13]. This is because those who ever heard about PNC were more likely knew also the importance of PNC visits and health risks during this period than others.

Mothers who delivered at health institution and received appointment to come back for postnatal care follow up were more likely to utilize postnatal care service. This is supported by studies from different parts of Ethiopia [14,15]. This could be explained as a positive effect of health information during counselling sessions for postpartum mothers on changing behaviour and practice for health care service utilization.

\section{Strength and Limitations}

The analysis used for study design and sampling procedures was more likely to yield accurate estimates. Using community based study design will help to address those mothers who were unable to visit health care facilities. In addition, this is the first study to report the prevalence and associated factors for postnatal care in the study area. Cross-sectional nature of the study limits the capacity to draw any causal implications.

\section{Conclusions}

The magnitude of postnatal care service utilization was higher as compared to other studies. However, it was much behind the national target for PNC service utilization. A history of ANC follows up, being informed about PNC and appointment for PNC were found to be a significant predictor of PNC service utilization. This implies that continuity of care has a positive effect on ser- 
vice utilization. Post-natal care should be strengthening by provision of information, education, counseling and communication for mothers at the community and facility level.

\section{Competing Interests}

The authors declare that they have no competing interests.

\section{Authors' Contributions}

MG involved in designing of the study, data collection, data analysis, drafting and critically reviewing the manuscript. Likewise, MS and FC involved in designing of the study, analysis of the data and critically reviewing the manuscript. All authors read and approved the final manuscript.

\section{Data Availability}

The datasets used and/or analyzed during the current study are available from the corresponding author on reasonable request.

\section{Consent for Publication}

Consent for publication is not applicable since there are no details, images, or videos relating to an individual person in this study.

\section{Funding}

This study was funded by Jimma University in partial fulfillment of the requirement for masters of Science degree in maternity health nursing.

\section{Author Details}

$M G$ is lecturer of maternal health nursing in institute of health Jimma University, MS is PhD fellow in institute of health, Jimma University and FC is lecturer of maternal health nursing in institute of health Jimma University. All authors are currently staff members in their respective department in Jimma University.

\section{Acknowledgements}

We would like to acknowledge Jimma University for giving us the opportunity to do this research. We also acknowledge the data collectors and Shebe sombo woreda health office.

\section{References}

1. NICE Clinical Guideline (2015) Ethiopian Federal Ministry of Health. post-natal care. 1-99.

2. (2015) Postnatal Care for Mothers and Newborns Highlights from the World Health Organization 2013 Guidelines. 1-8.

3. WHO, UNICEF, UNFPA WBG and UNPD (2015) Trends in Maternal Mortality: 1990 to 2015: Estimates Developed by WHO, UNICEF, UNFPA, The World Bank and the United Nations Population Divisions. 32: 1-55.

4. The DHS Program (2016) Ethiopia Demographic and Health Survey. 187-189.
5. (2010) WHO Technical Consultation on Postpartum and Postnatal Care.

6. Lawn JE, Cousens S, Zupan J, Lancet Neonatal Survival Steering Team (2005) 4 million neonatal deaths: When? Where? Why? Lancet 365: 891-900.

7. (2018) Optimizing postpartum care: ACOG committee opinion. Am Coll Obstet Gynecol Women's Health Care 131: 140-150.

8. Limenih MA, Endale ZM, Dachew BA (2016) Postnatal Care Service Utilization and Associated Factors among Women Who Gave Birth in the Last 12 Months prior to the Study in Debre Markos Town, Northwestern Ethiopia: A community-based cross-sectional study. Int J Reprod Med 2016: 1-7.

9. Teklehaymanot AN, Niguse D, Tesfay A (2017) Early postnatal care service utilization and associated factors among mothers who gave birth in the last 12 months in Aseko District, Arsi Zone, South East Ethiopia in 2016. J Women Heal Care 6: 1-12.

10. Abuka Abebo T, Jember Tesfaye D (2018) Postnatal care utilization and associated factors among women of reproductive age Group in Halaba Kulito Town, Southern Ethiopia. Arch Public Health 76: 9.

11. Facha W, Alemayehu M, Meskele M, Fikadu T (2017) Couples' opinion and women's utilization of postnatal care service in Wolaita Zone, Southern Ethiopia: A community based mixed study. Sci J Public Heal 5: 288-293.

12. Idris Usman Takai, Haruna Dantaro Dlakwa, Mohammed Bukar, Bala Mohammed Audu, Aliyu Salihu Kwayabura (2015) Factors responsible for under-utilization of postnatal care services in Maiduguri, North-Eastern Nigeria. Sahel Med Journal 18: 109-115.

13. Khanal V, Adhikari M, Karkee R, Gavidia T (2014) Factors associated with the utilisation of postnatal care services among the mothers of Nepal: Analysis of Nepal demographic and health survey 2011. BMC Womens Health 14: 19.

14. Abera S, Ayalneh B GA (2018) Postnatal care services utilization and its associated factors among women who gave birth in the past one year in Gulele sub city, Addis Ababa, Ethiopia. J Heal Med Nurs 46: 238-246.

15. Alemayeh H, Assefa H, Adama Y (2014) Prevalence and factors associated with post natal care utilization in abi - adi town, Tigray, Ethiopia: A cross sectional study. IJPBSF Int J Pharm Biol Sci Fundam 8: 2278-3997.

16. Yunus A, Iqbal S, Munawar R, Zakar R, Mushtaq SK, et al. (2013) Determinants of postnatal care services utilization in Pakistan- Insights from Pakistan Demographic and Health Survey (PDHS) 2006-07. Middle-East J Sci Res 18: 14401447.

17. Belemsaga DY, Kouanda S, Goujon A, Kiendrebeogo JA, Duysburgh E, et al. (2015) A review of factors associated with the utilization of healthcare services and strategies for improving postpartum care in Africa. Africa Focus 28: 83-105.

18. Tesfahun F, Worku W, Mazengiya F, Kifle M (2014) Knowledge, perception and utilization of postnatal care of mothers in Gondar Zuria District, Ethiopia: A cross-sectional study. Matern Child Health J 18: 2341-2351.

19. Aregay A, Alemayehu M, Assefa H, Terefe W (2014) Factors associated with maternal health care services in Enderta District, Tigray, Northern Ethiopia: A cross sectional study. Am J Nurs Sci 3: 117-125.

20. Workineh YG, Hailu DA (2014) Factors affecting utilization of postnatal care service in Jabitena district, Amhara region, Ethiopia. Sci J Public Heal 2: 169-176. 